https://doi.org/10.52449/1857-4114.2021.37-1.15

CZU: 612.172:616.151.1:796.8-051

\title{
AUTONOMIC RHYTHM REGULATION OF ELITE WRESTLERS WITH DIFFERENT DOMINANCE OF BRAIN HEMISPHERE
}

\author{
Korobeynikov Georgiy ${ }^{1}$, ORCID: 0000-0002-1097-4787 \\ Korobeynikova Lesia ${ }^{2}$ \\ Gorașcenco Alexandr ${ }^{3}$, ORCID: 0000-0002-8269-7862 \\ Vorontsov Andrey ${ }^{4}$, ORCID: 0000-0002-4319-6192 \\ Ludanov Kirill , ORCID: 0000-0002-4536-7477 \\ 1,2,4,5 National University of Physical Education and Sports of Ukraine, Kiev \\ ${ }^{3}$ State University of Physical Education and Sports, Chisinau, Republic of Moldova
}

\begin{abstract}
The results of a study of the autonomous regulation of the heart rate in elite wrestlers with different dominance of the cerebral hemispheres were present in the manuscript 23 elite wrestlers. Were examined members of the National Team of Ukraine in Greco-Roman wrestling, aged 22-34 years-old. A body composition monitor "Omron BF511" and a computer electrocardiograph "Fazagraf" were used.

It was revealed that elite wrestlers with a dominance of the right hemisphere have more intense regulation of the heart rhythm compared to wrestlers with a dominance of the left hemisphere of the brain. With an increase in the tension of the system of autonomous regulation of the heart rhythm in wrestlers with the dominance of the right hemisphere of the brain, the activation of the central and sympathetic division of regulation occurs. For the purpose of a more effective preparation process and in the development of individual training programs for elite wrestlers, it is necessary to determine the dominance of the cerebral hemispheres.
\end{abstract}

Keywords: elite wrestlers, autonomous regulation of heart rhythm, dominance of the cerebral hemispheres.

\section{Introduction}

Modern sport of high achievements is characterized by the search for genetically determined characteristics for the development of individual training programs for elite athletes. Among the existing approaches to the individualization of the training process, the characteristics of psychophysiological functions are traditionally used. This characteristics are responsible for the perception and processing of information in athletes [1,2]. Thus, the main direction of research is aimed at studying the neurodynamics and psychomotor functions in athlete as a indicator of functional state $[3,4]$.
Besides from, the problem of ensuring the optimal functioning of the athlete's organism in conditions of increasing intensity of physical and psycho-emotional load are very actual for wrestling [5,6].

One of the genetically determined personal characteristic of human is functional asymmetry of brain. Our previous studies show that among elite wrestlers the one-third have functional brain asymmetries, with dominance of right hemispheric [7].

However, for the implementation of technical and tactical actions in the competitive activity, in addition to the psychomotor component, it is also important the functional state and the athlete's ability to 
mobilize the adaptive reserves. One of the informative indicators of adaptive reactions of an athlete's organism under conditions of intense muscular activity is the autonomous regulation of the heart rhythm [8].

Aim of the study was to investigate the autonomic regulation of heart rhythm in elite athletes with different dominance of brain hemisphere.

Research methodology and organization

The 23 elite wrestlers, members of Ukrainian Greco-Roman Team aged 22-34 were examined.

From all of athletes was given the agreement to take part in the study according to recommended of biomedical ethics committee [9].

The autonomic heart rhythm regulation was studied by "Fazagraf" computer electrocardiograph. Statistical and spectral characteristics of heart rate variability were recorded. The functional asymmetry of brain hemispheres was studied using the "Color \& Word Test" [10]. Statistical analysis was performed using the "Statistica 7.0" software package. Methods of nonparametric statistics were used. To assess the significance of the differences, the Wilcoxon signed rank sum test was used.
Research results and their discussion

According to the results of the study of functional asymmetry of the brain, all athletes were divided into two typological groups: with a predominance of the left hemisphere (13 athletes) and right hemisphere (10 athletes) dominance.

Analysis of heart rate variability indices in wrestlers with different dominance of the cerebral hemispheres showed that with the predominance of right hemispheric dominance, increased values of Mean RR, STD RR and RR triangular index are observed (Table 1)

According to the changes in STD RR and triangular index, an increase in the degree of tension of autonomous regulation of heart rhythm in wrestlers with left hemispheric dominance was revealed in comparison with the group of wrestlers in right hemispheric dominance (Table 1). This circumstance indicates an increase of total influence the sympathetic and parasympathetic tone on the sinus node of the heart in athletes with left hemispheric dominance.

The results of spectral analysis of heart rate in wrestlers with different dominance of brain hemisphere were presented in Table 2.

Table 1. Variability of heart rhythm in elite wrestlers with different dominance of brain hemisphere

\begin{tabular}{|c|c|c|c|c|c|c|}
\hline \multirow[b]{2}{*}{ Values } & \multicolumn{3}{|c|}{ Right hemispheric dominance $(n=10)$} & \multicolumn{3}{|c|}{ Left hemispheric dominance $(n=13)$} \\
\hline & Mediana & $\begin{array}{c}\text { Lower } \\
\text { quartile }\end{array}$ & $\begin{array}{c}\text { Upper } \\
\text { quartile }\end{array}$ & Mediana & $\begin{array}{l}\text { Lower } \\
\text { quartile }\end{array}$ & $\begin{array}{c}\text { Upper } \\
\text { quartile }\end{array}$ \\
\hline $\begin{array}{c}\text { Mean RR, } \\
\text { ms }\end{array}$ & 1046,00 & 722,30 & 1312,90 & $980,16^{*}$ & 722,30 & 1281,90 \\
\hline $\begin{array}{c}\text { STD RR, } \\
\text { ms }\end{array}$ & 115,51 & 887,80 & 146,60 & $87,32 *$ & 67,800 & 109,10 \\
\hline $\begin{array}{c}\mathrm{RR} \\
\text { triangular } \\
\text { index } \\
\end{array}$ & 59,40 & 46,10 & 83,20 & $14,02^{*}$ & 8,52 & 23,33 \\
\hline
\end{tabular}

Note: $*$ - for concerning to wrestlers with right hemispheric dominance $\mathrm{p}<0,05$. 
Table 2. Spectral analysis of heart rhythm in elite wrestlers with different dominance of brain hemisphere

\begin{tabular}{|c|c|c|c|c|c|c|}
\hline \multirow{2}{*}{ Values } & \multicolumn{4}{|c|}{ Right hemispheric dominance $(\mathrm{n}=10)$} & \multicolumn{3}{|c|}{ Left hemispheric dominance $(\mathrm{n}=13)$} \\
\cline { 2 - 7 } & Mediana & $\begin{array}{c}\text { Lower } \\
\text { quartile }\end{array}$ & $\begin{array}{c}\text { Upper } \\
\text { quartile }\end{array}$ & Mediana & $\begin{array}{c}\text { Lower } \\
\text { quartile }\end{array}$ & $\begin{array}{c}\text { Upper } \\
\text { quartile }\end{array}$ \\
\hline VLF, $\mathrm{ms}^{2}$ & 149,57 & 87,50 & 242,60 & $4666,37^{*}$ & 3332,00 & 7081,00 \\
\hline LF, $\mathrm{ms}^{2}$ & 11528,58 & 312,00 & 61346,00 & $2259,12^{*}$ & 275,00 & 6243,00 \\
\hline $\mathrm{HF}, \mathrm{ms}^{2}$ & 2620,42 & 875,00 & 3919,00 & $1545,37^{*}$ & 1006,00 & 1720,00 \\
\hline $\mathrm{LF} / \mathrm{HF}$ & 1,59 & 0,87 & 2,27 & $2,19^{*}$ & 1,83 & 4,92 \\
\hline
\end{tabular}

Note: $*$ - for concerning to wrestlers with right hemispheric dominance $\mathrm{p}<0,05$.

The analysis shows that in wrestlers with left hemispheric dominance, the value of verylow-frequency spectrum of heart rate fluctuations (VLF) is significantly higher than in wrestlers with right hemispheric dominance. However, in terms of the low-frequency spectrum of heart rate fluctuations (LF), a feedback is observed. This is due to the fact that in wrestlers with left hemispheric dominance the activation of the central mechanisms of regulation of the heart rhythm is observed, while in wrestlers with right hemispheric dominance - the sympathetic tone of the autonomic nervous system.

The studies have shown that wrestlers with right hemispheric dominance have significantly higher values of the highfrequency spectrum of heart rate (HF) oscillations. This fact indicates the activation of the parasympathetic tone of the autonomic nervous system. Analysis of the autonomic balance indicator (LF/HF) indicates a more intense character of autonomic regulation in wrestlers with left hemispheric dominance.

The functional asymmetry of the human brain is a property that determines the personal characteristics of a person. The functional asymmetry of the brain is largely associated with the manifestation of psychosomatic and autonomic reactions of the athlete's organism [7].

That is why for an objective assessment of the functional state of the athlete's and the construction of the training process the dominance of brain hemisphere determining is very important. One of the objective indicators of the adaptive process of athlete's is the analysis of heart rate variability [8]. The effectiveness of activation of the regulatory mechanisms of the circulatory system also depends on the personal properties of athletes $[2,3,4]$.

In our study it was found that wrestlers with left-hemispheric dominance are characterized by a slowdown in the heart rate due to the activation of the parasympathetic tone and a decrease in the tension level of the autonomic regulation system. The wrestlers with right hemispheric dominance showed a higher level of autonomic regulation tension due to the activation of central and sympathetic mechanisms.

\section{Conclusions}

1. Elite wrestlers with dominance of the right hemisphere have more intense regulation of the heart rate compared to wrestlers with dominance of the left hemisphere of the brain.

2. An increase of tension of the autonomous regulation of heart rhythm in wrestlers with the dominance of the right hemisphere of the brain is associated with the activation of the central mechanisms and sympathetic tone.

3. For a more effective preparation process and in the development of personal training programs for elite wrestlers, it is necessary to determine the dominance of the brain hemisphere. 


\section{References:}

1. Podrigalo L., Iermakov S., Potop V., Romanenko V., Boychenko N. (2017). Special aspects of psycho-physiological reactions of different skillfulness athletes, practicing martial arts. Journal of Physical Education and Sport; 17(1): 519-26. doi: 10.7752/jpes.2017.s2078.

2. Lyzohub V., Chernenko N., Palabiyik A. (2019). Neurophysiological mechanisms of regulation of sensorimotor reactions of differentiation in ontogenesis. Journal of Cellular Neuroscience and Oxidative Stress; 11(1): 805- 814.

3. Chernozub A., Korobeynikov G., Mytskan B., Korobeinikova L., Cynarski W.J. (2018). Modelling mixed martial arts power training needs depending on the predominance of the strike or wrestling fighting style. Ido movement for culture. Journal of Martial Arts Anthropology; 18(3):2836. doi: 10.14589/ido.18.3.5.

4. López-González D.E., Miarka B. (2013). Reliability of a new time-motion analysis model based on technical-tactical interactions for wrestling competition. International Journal of Wrestling Science. Jun 1;3(1):21-34. doi:10.1080/21615667.2013.10878967.

5. Mirzaei B., Curby D., Rahmani-Nia F., Moghadasi M. (2009). Physiological profile of elite Iranian junior freestyle wrestlers. The Journal of Strength \& Conditioning Research; 23(8): 2339-44. PMID: 19826290. doi: 10.1519/JSC.0b013e3181bb7350.

6. Curby D. (2016). Effect of uniform color on outcome of match at Senior World Wrestling Championships 2015. International Journal of Wrestling Science; 6(1): 62-4. DOI: 10.1080/21615667.2016.1210266.

7. Korobeynikov G., Korobeynikova L. (2014). Functional brain asymmetry and cognitive functions in elite wrestlers. International Journal of Wrestling Science; 4(1): 26-34. DOI: 10.1080/21615667.2014.10878997.

8. Korobeynikov G., Korobeynikova L., Potop V., Nikonorov D., Semenenko V., Dakal N., Mischuk D. (2018). Heart rate variability system in elite athletes with different levels of stress resistance. Journal of Physical Education and Sport. Jun 1; 18(2):550-554. doi:10.7752/jpes.2018.02079.

9. Егоренков А.И., Медведев В.В. (2019). Концептуальные направления развития институциональной системь биоэтической деятельности в Национальной Академии Медицинских Наук Украины = Conceptual development of the bioethical institutional system in the National Academy of Medical Sciences of Ukraine. C22.:430.

10. Stroop J.R. (1935). Studies of interference in serial verbal reactions. Journal of experimental psychology; 18(6): 643-8. 